\title{
A Novel ZVS Bidirectional DC-DC Converter for Fuel Cell Applications
}

\author{
A. Salami and E. Rezaei
}

\begin{abstract}
In this paper a new bidirectional dc-dc converter for a fuel cell system is proposed that has a current tripler rectifier in its low voltage side. The converter is based on a ZVS half bridge topology with current tripler rectifier at the secondary side of transformer. The asymmetrical PWM is used in the converter to achieve ZVS of power switches and to regulate the output voltage at the desired value. The proposed converter has the advantages of high efficiency, high power density and simple circuit configuration. The operation principle and system analysis are described and discussed. Finally, the simulation results for the proposed converter are provided to verify the theoretical analysis.
\end{abstract}

Index Terms-Bidirectional dc-dc converter, current tripler rectification, fuel cell, zero voltage switching.

\section{INTRODUCTION}

Fuel cell is one of the very promising renewable energy sources for power generation in distributed generation technologies. It also can be used in high power and low power applications such as electric vehicle, communication systems. The main disadvantage of fuel cell is slow dynamic response due to the natural electrochemical reactions and hence requires Power Conditioning System (PCS) to interface the load. PCS plays an important role to deliver the power from the fuel cell to various loads. All PCS should be designed and operated with high efficiency, high performance and high reliability. There are four types of PCS configurations for fuel cell systems that are proposed in [1]. The best one type of these configurations is ones that have a bidirectional dc-dc converter between the low voltage battery and high voltage bus. High voltage bus may be directly connected to the fuel cell or may be connected to it via an isolated high frequency dc-dc converter. But the important thing in all case is that we need a bidirectional dc-dc converter. Among the proposed topologies for bidirectional dc-dc converter, full bridge and half bridge converters are good candidate for medium and high power applications. In some paper bidirectional dc-dc converter with full bridge topology in both sides is presented [2]-[4]. The advantages of these converters are symmetric configuration and ZVS due to PWM and they have no extra reactive components. But in such converters the output voltage is proportional to load however they can transmit more power in comparison with half bridge topology. In some literatures converters are consist of half bridge in both

Manuscript received July 20, 2012; revised August 21, 2012.

A. Salami is with the Arak University of Technology, Iran (e-mail: salami@arakut.ac.ir, a_salami@iust.ac.ir, abs.salami@gmail.com). side [5]-[8]. These converters can be controlled easily and they have not neglecting current that is major problem in dual full bridge dc-dc converters. Another bidirectional converter have half bridge or full bridge in high voltage side and center tapped rectifier in low voltage side [9]-[11].These configurations have advantages of simple circuit and easy implementation but they have a low current output due having only one self in their output. A dc-dc converter with a novel current tripler rectifier is presented in [12]. But, only power flow in one direction is inspected. In this paper a new bidirectional dc-dc converter based on a half bridge converter with asymmetrical PWM scheme in high voltage and current tripler rectification in low voltage is presented to achieve bidirectional power flow. The proposed converter has advantage of high current output capability with smaller reactive components in comparison with converters that use other rectifier topologies in their low voltage side. The asymmetrical PWM scheme can help the power switches at high voltage side to turn on at ZVS. To safety requirement, the isolated transformer is used between the low voltage battery and high voltage bus to achieve voltage step up or step down. The operation principle and system analysis of proposed bidirectional converter are presented herein. In order to demonstrate the effectiveness based on the characteristic performances, simulations are carried out in different positions.

\section{CiRCUIT ANALYSIS}

In order to combine advantages of half bridge with ZVS-PWM control and current tripler rectifier that has higher power flow than other rectifier topologies, a novel bidirectional dc-dc converter is proposed.

Fig. 1 shows the circuit configuration of the proposed isolated bidirectional DC-DC converter. The half bridge converter is adapted in high voltage side and a current tripler rectifier is used in low voltage side for increasing power flow of proposed converter. When power flow from high voltage side to low voltage side, the converter operates in buck mode for charging battery from fuel cell. When power flows from low voltage side battery to high voltage side, the converter operates in boost mode for draw the energy from battery. $S_{1}$ and $S_{2}$ in half bridge side and $S R_{1}$ and $S R_{2}$ in battery side operate complementary each other.

\section{A. Buck Mode Operation}

When power flows from high voltage side to low voltage side, the converter operates in buck mode for charging battery from fuel cell. In the proposed converter $L_{m}$ is the transformer magnetizing inductance. $L_{r}$ is the resonant inductance for ZVS. 


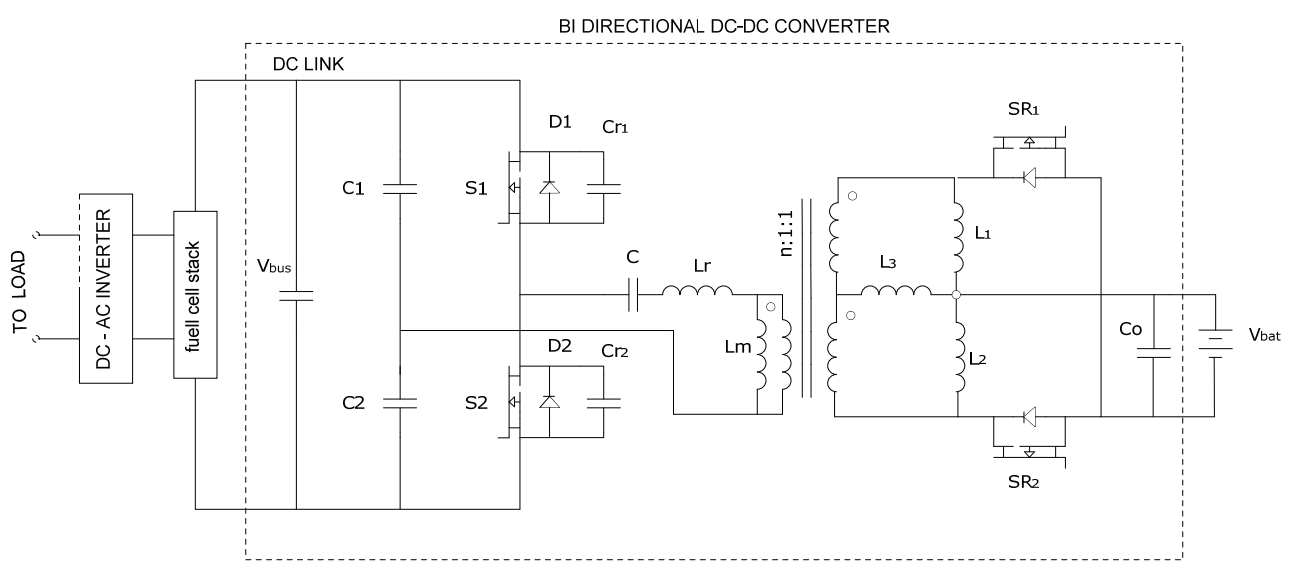

Fig. 1. Topology of proposed converter.

$C_{r 1}$ and $C_{r 2}$ are the output capacitance of $\mathrm{S}_{1}$ and $\mathrm{S}_{2}$. Also $\mathrm{C}_{\mathrm{r} 1}$, $C_{r 2}$ and $L_{r}$ are resonant to achieve ZVS turn on of $S_{1}$ and $S_{2}$. In the secondary side $S R_{1}$ and $S R_{2}$ are synchronous switches to achieve full wave rectification. The output inductors are used for reduce the output current ripple. The turn on conduction loss in secondary side is very low due to use synchronous switches. Before the system analysis, we should make some assumption.

-Clamp capacitance $C$ is large enough so that the capacitor voltage $V_{c}$ is a constant value and it is much larger than the output capacitance of two power switches $\left(C>>C_{r 1}, C_{r 2}\right)$.

-Leakage inductance $L_{r}$ is smaller than the magnetizing inductance $L_{m}$.

There are eight operating mode during one switching cycle according to the conduction state of all switches. Switch $S_{1}$, synchronous switch $S R_{2}$ and diode $D_{4}$ are conducting before starting time.

\section{B. Boost Mode Operation}

The proposed converter can draw power from battery voltage $V_{b a t}$, when the high voltage $V_{b u s}$ is lower than desired value, tripler synchronous rectifier is operated in an asymmetrical PWM with an overlapping to regulate the high voltage $V_{\text {bus }}$. During one switching cycle, there are eight operating modes in converter. Switch $S R_{1}, S R_{2}$ and synchronous switch $S_{1}$ are conducting before starting time.

\section{Simulation RESUlts}

The time intervals in some modes are very short in the proposed converter at buck and boost operations. Thus, only those modes have long times are used to drive the voltage transfer ratio of the proposed converter. In mode $1, \mathrm{~S}_{1}$ and $\mathrm{SR}_{2}$ are in on state and the voltage across $L_{r}$ and $\mathrm{L}_{\mathrm{m}}$ is $V_{\text {bus }} / 2-\mathrm{V}_{\mathrm{c}}$.

In mode $5, \mathrm{~S}_{2}$ and $\mathrm{SR}_{1}$ are in on state and the voltage across $L_{r}$ and $L_{m}$ is $V_{\text {bus }} / 2-V_{c}$. Based on the voltage second balance across $L_{r}$ and Lm, in mode 1 and 5, one can obtain the clamp capacitor voltage.

$$
V_{c}=(D-0.50) V_{\text {bus }} .
$$

where D is the duty ratio of the switch $S_{1}$. We can obtain the output voltage equation.

$$
V_{b a t}=\frac{2 D(1-D)}{n}
$$

Based on the voltage second balance across $L_{3}$, in modes 1 and 5 , we can obtain the voltage transfer ratio in buck operation.

$$
A_{v}=\frac{2 D(1-D)}{n} \text {. }
$$

The voltage transfer ratio shows that $\mathrm{D}=0.5$ is the optimal value for duty cycle. When the input voltage is minimum Vbus, the duty cycle $\mathrm{D}$ is close to maximum value $(\mathrm{D}=0.5)$, to deliver power from high voltage side to low voltage side. In this case, the higher current will flow through power switch $S_{1}$ and $S_{2}$. To maintain the clamp voltage $V_{C}$, the average current flows through capacitor $\mathrm{C}$ must be zero. If the allowed voltage ripple in clamp capacitor $\Delta V_{c}$ is given, the required capacitance of the clamp capacitor $\mathrm{C}$ can be determined.

$$
C=\frac{2 I_{L} D(1-D) T}{\Delta V_{c} n} .
$$

If we consider that, the current ripple of each output inductor is constant; we can determine all of output inductors.

$$
\begin{aligned}
& L_{1}=L_{2}=\frac{(1-D) V_{b a t} T}{\Delta i_{L_{1,2}}} . \\
& L_{3}=\frac{(1-2 D) V_{b a t} T}{\Delta i_{L_{3}}} .
\end{aligned}
$$

To simulation, the power of converter is selected 420 watts and is operated in $100 \mathrm{kHz}$. The nominal voltage at low voltage side is $42 \mathrm{v}$ that may be varies between 30 to 45 volts. The nominal voltage at high voltage side is $350 \mathrm{v}$ that may be varies between 250 to 400 volts. If we select the duty cycle $\mathrm{D}=0.5$, then the circuit will be symmetric but we should select the duty cycle between 0.3 and 0.48 for desired voltage. Based on these duty cycles we can calculate transformer ratio:

$$
n=2 D_{\text {max }}\left(1-D_{\text {max }}\right) \frac{V_{\text {bus, } \max }}{V_{\text {bat, } \text { min }}}=6.66 .
$$


Since we consider the power of converter $420 \mathrm{w}$, the output current, equals $10 \mathrm{~A}$ and consequently if the allowed ripple voltage on capacitor $\mathrm{C}$ is $10 \mathrm{~V}$, then the capacitance of this capacitor can be determined:

$$
C=\frac{2 I_{L} D_{\max }\left(1-D_{\max }\right) T}{\Delta V_{c} n}=0.75 \mu \mathrm{F} .
$$

If the allowed current on inductor L3 is considered \%25, we can determine it:

$$
L_{3}=\frac{\left(1-2 D_{\min }\right) V_{b a t, \max } T}{2 \Delta i_{L_{3}}}=36 \mu \mathrm{H} .
$$

If we consider inductors $L_{1}$ and $L_{2}$ to be equal $L_{3}$, then the ripple current of these inductor will be \%75. The selected power MOSFETs for simulation are IRF460 in half bridge side that can withstand voltage up to $500 \mathrm{~V}$ and current up to 20A and IRF260 as power MOSFETs switch at low voltage side that can withstand voltage up to $250 \mathrm{~V}$ and current up to 38A. To ensure ZVS, selecting of $C_{r}$ and $L_{r}$ are very important so that resonant frequency will be bigger than switching frequency and Resonant amplitude will be enough big. For this we can use $L_{r}=8 \mu \mathrm{H}$ and $\mathrm{C}_{\mathrm{r}}=650 \mathrm{PF}$.

The key waveforms of this converter are shown in Fig. 2 and Fig. 3 for both modes buck and boost operation respectively. In the proposed converter, the measured efficiency is about $88 \%$ for 420 watt in buck mode operation and this efficiency is about $91 \%$ in boost mode operation. From Fig. 4 we can see that the efficiency of proposed converter is higher than efficiency of the converter with push pull rectifier for both buck and boost operations, because output inductors in the proposed converter in comparison with one output inductor in the converter using current center rectifier in its low voltage side ensure more current at output so we can get more power at output, however these three inductors are smaller than one inductor in converter with push pull rectifier. Consequently, the proposed converter has more power output than converter with push pull rectifier in buck and boost operations. We can discover the advantages of proposed converter in compare with converter that push pull rectifier are used at its secondary side of transformer.

These advantages are consisting of same voltage output with smaller inductor and more power output in same condition.
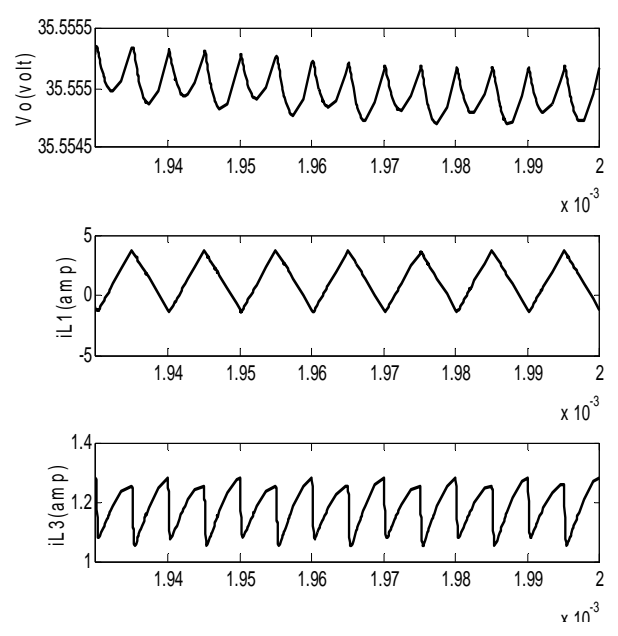

Fig. 2. Waveforms of proposed converter in buck operation.
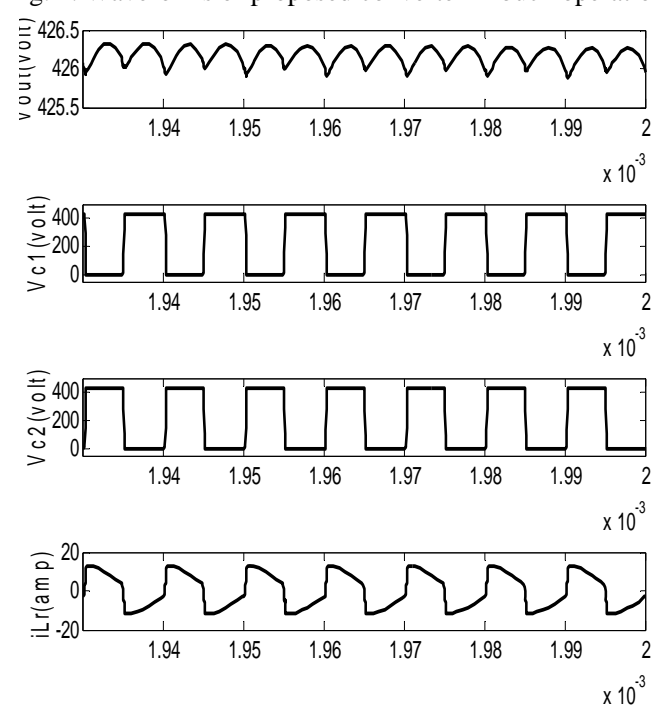

Fig. 3. Waveforms of proposed converter in boost operation (a)

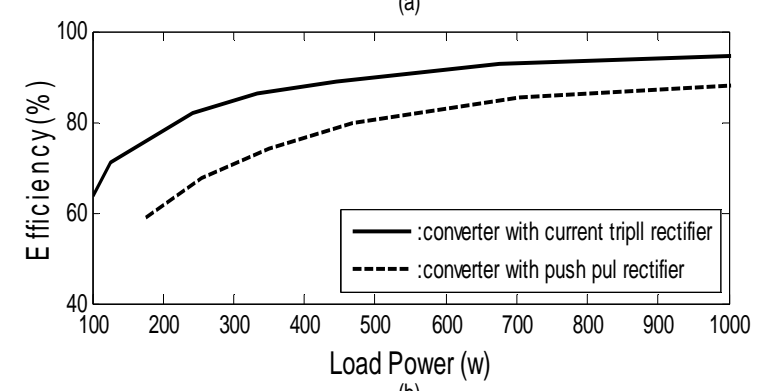

(b)

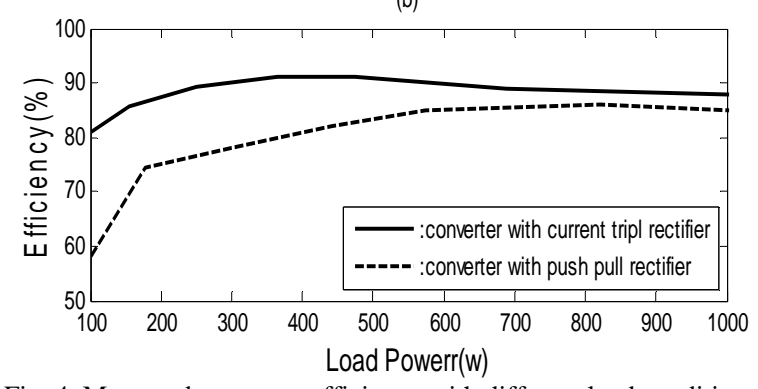

Fig. 4. Measured converter efficiency with different load conditions, (a) Buck operation and (b) boost operation.

\section{CONCLUSION}

The operating principle and mathematical analysis of a bidirectional DC-DC converter with tripler synchronous rectifier were presented in this paper and we saw that current tripler rectifier can be used as converter in buck and boost mode operations. The asymmetrical pulse width modulation is used in the circuit to regulate the output voltage. With the aid of capacitance of switch at high voltage side and with leakage inductance, the power switches at high voltage side are operated at ZVS turn on. A simulation example at 420 watt in this paper is provided and we saw, this converter which using tripler current rectifier at its low voltage side in comparison with converters that use another rectifiers such as push pull, has an extra power density and consequently with this topology we can have more power density and more efficiency.

\section{REFERENCES}

[1] D. K. Choi, B. K. Lee, S. W. Choi, C. Y. Won, and D. W. Yoo, “A novel power conversion circuit for cost-effective battery-fuel cell 
hybrid systems," Journal of Power Sources, vol. 152, 2005, pp. 245-255.

[2] C. Mi1, H. Bai1, C. Wang, and S. Gargies, "Design and control of dual H-bridge-based isolated bidirectional DC-DC converter," IET Power Electron., 2008, vol. 1, no. 4. pp. 507-517.

[3] S. Han, "Dual Active Bridge Buck-Boost Converter," IEEE Transactions on Power Electronics, July 2009, vol. 24, no. 7, pp.1826-1838.

[4] L. Zhu, "A Novel Soft-Commutating Isolated Boost Full-Bridge ZVS-PWM DC-DC Converter for Bidirectional High Power Applications," IEEE Transactions on Power Electronics, March 2006, vol. 21, no. 2, pp.422-429.

[5] M. Gang, Q. Wenlong, and L. Yuanyuan, "A Novel Soft Switching Bidirectional DC/DC Converter and Design Consideration,” Power Electronics and Applications, 2009. EPE '09. 13th European Conference on Issue Date, pp. 8-10, Sept. 2009, pp.1-10.

[1] Z. Zhang and C. Ole, "A Novel PPFHB Bidirectional DC-DC Converter for Supercapacitor Application,” Clean Electrical Power, 2009 International Conference on Issue Date, pp. 9-11, June 2009, pp. 350-354.

[6] F. Z. Peng, H. Li, G. J. Su, and J. S. Lawler, "'A New ZVS Bidirectional DC-DC Converter for Fuel Cell and Battery Application," IEEE Transactions on Power Electronics, january 2004 ,vol.19, no. 1, pp.54-65.
[7] T. M. E. Hiraki, T. Tanaka, and M. Nakaoka, “A New Soft-Switched Bidirectional DC-DC Converter Topology for Automotive High Voltage DC Bus Architectures," Vehicle Power and Propulsion Conference, 2006. VPPC '06. IEEE, 2006, pp.1-6.

[8] F. G. Capponi, P. Santoro, and E. Crescenzi, “A Bidirectional DC/DC Converter For Optimal Power Flow Regulation in Supercapacitor Applications," Industry Applications Conference, 2007. 42nd IAS Annual Meeting. Conference Record of the 2007 IEEE, pp. 2009-2015.

[9] S. Pattnaik, A. K. Panda, K. K. Mahapatra, S. Pattnaik, A. K. Panda, and K. K. Mahapatra, "A Novel Improved Soft Switching PWM DC-DC Converter," India Conference, 2008. INDICON 2008. Annual IEEEIssue Date, pp. 11-13 Dec. 2008, vol. 1, pp. 92-97.

[10] B. R. Lin, C. L. Huang, and Y. E. Lee, "Asymmetrical pulse-width modulation bidirectional DC-DC converter," IET Power Electron., 2008, vol. 1, no. 3. pp. 336-347.

[11] L. Yao, H. Mao, and I. E. Batarseh, “A Rectification Topology for high current isolated DC-DC Converter," IEEE Transactions on Power Electronics, July 2007, vol. 22, no. 4, pp.1522-1530.

A. Salami was born in Islamic Republic of Iran on 1974. He received the B.S. degree from Isfahan University Technology, M.S., and Ph.D. degree from Iran University of Science and Technology in electrical engineering in 1996, 1999 and 2005, respectively. He has been working as an Assistant Professor at the Department of electrical Engineering, Arak University Technology. He has published more than 20 paper on power system modeling and simulation, artificial methods and planning issues. 